\title{
FACTORS AFFECTING THE CHOICE OF LEARNING RESOURCES BY STUDENTS
}

\author{
Xue Bai, Virginia State University, xbai@vsu.edu \\ Ade Ola, Virginia State University, aola@nova.edu \\ Yingjin Cui, Northern Virginia Community College, ycui@nvcc.edu
}

\begin{abstract}
With so much learning resources available at the click of a button, do we need textbooks? This question becomes especially provocative when faced with the prospect of having students spend hundreds of dollars every semester. In an attempt to lower the cost of a higher education, Open Educational Resources (OER) programs seek to replace the current model of teaching from textbooks with a curriculum comprised of freely available information. However, research has shown that there is a decline in of reading of texts by students, regardless of the format of texts. There are also conflicting research results on whether textbook reading in university-level courses is correlated with improvements in student grades. The conflicting results raise many questions about the role of the textbook in tertiary education. In an effort to answer these questions, we conducted a preliminary survey on textbook usage in several undergraduate introductory programming courses. The objective of the study is to examine the factors that motivate students to use required textbooks, determine their preferred textbook format, and investigate how students learn and prepare to meet course requirements. In the study, the principal component analysis was used to identify the learning factors that most influence the resources that students use to prepare for their classes. The findings in the study suggest that "Perceived Benefit" and "Alternatives" were the most important factors impacting the use of textbooks. The data analysis from the study provides insight into the potential benefits of the use of a textbook. The results of this study and the conflicting results from previous research on the use and efficacy of textbooks appear to suggest that the textbook as a learning instrument needs to change to support "How People Learn.”
\end{abstract}

Keywords: Learning Resources, OER, Information Technology (IT), and Online Learning

\section{INTRODUCTION}

The textbook has always been a central vehicle for instruction and learning, particularly in formal education settings. Traditionally, textbooks have been used to guide instruction in courses within a curriculum, and serve as the singular source of content material in a particular branch of study. Even with the availability of other learning materials such as videos, simulators, interactive games, and tutoring systems, the textbook is the definitive source of content for the knowledge and skills that students should acquire within the prescribed curriculum. Therefore, instructors continue to promote textbook reading and expect students to complete assigned readings as a way for students to improve their academic performance.

Wandersee (1988) stated that reading leads to better grades, which would lead one to assume that students read their textbooks in order to prepare for examinations. However, it has been shown that there is a decline in the rate of reading of texts by students (Burchfield \& Sappington, 2000). Additionally, a significant proportion of college students do not read course texts in preparation for class sessions or examinations (Aagaard \& Skidmore, 2009; Clump, Bauer, \& Bradley, 2004; Sikorski, Rich, Saville, Buskist, Drogan, \& Davis 2002). Sikorski et al. (2002) reported that students spend less than three hours per week reading their textbooks, which is significantly less than university recommendations of at least 2 hours of study time for every class credit (Clump et al. 2004). The research on student-reported reading compliance in both introductory and advanced courses is low, ranging from about $20 \%$ to 70\% (Burchfield and Sappington 2000; Sikorski et al. 2002; Marchant 2002; Clump, Bauer, and Bradley 2004; Podolefsky and Finkelstein 2006; Starcher and Proffitt 2011; Berry, Cook, Hill, \& Stevens. 2011; French, Taverna, Neumann, Kushnir, Harlow, Harrison, and Serbanescu., 2015).

Perhaps even more alarming, there are conflicting results about whether textbook reading in university-level courses is correlated with improvements in student grades. Podolefsky and Finkelstein (2006) conducted a survey on 


\section{Issues in Information Systems}

Volume 21, Issue 3, pp. 66-71, 2020

textbook usage in four introductory college physics courses. The results showed that while over $97 \%$ of students bought the required textbook, less than $41 \%$ reported that they read regularly. Their research also found that there was little (or no) correlation between reading habits and course grades. Further analysis of how and why students read indicated little or no variation in the perceived value of the textbook for course components tightly coupled to grades. Similar results were found across conceptual-, algebra-, and calculus-based courses with different instructors and textbooks (Podolefsky and Finkelstein, 2006). On the other hand, Sappington, Kinsey, and Munsayac (2002) found that performance of upper level psychology students on an initial surprise reading quiz, which largely measured reading compliance rather than comprehension, predicted lower exam scores. Those students who passed the quiz averaged $84 \%$ on the exam, while those who failed the quiz averaged $68 \%$ on the exam. In a study focused mainly on textbook aids, Landrum, Gurung, and Spann (2012) reported a significantly positive correlation between "percentage of reading completed" and higher quiz/final grades in a general psychology course.

The conflicting results described above raise many questions about the role of the textbook in tertiary education. Given the conflicting results on the use and efficacy of textbooks, is there any point in even assigning one? If students are reluctant to use the textbook, how do they prepare for tests or gain the fundamental knowledge to meet course requirements? Alternatively, if instructors believe that textbook reading or any other format of reading materials promote a deeper understanding of the course material and life-long learning skills, are there strategies that instructors should implement in their courses to promote textbook reading? In an effort to answer these questions, we conducted a preliminary survey on textbook usage in several undergraduate and graduate courses across various disciplines. The objective of the study is to examine the factors that motivate students to use required textbooks, determine their preferred textbook format, and investigate how students learn and prepare to meet course requirements.We live in an information society. Most people live and work within the context of information technology (Abratt, Nel, \& Higgs, 1992). IT enhances leisure time and enriches culture by expanding the distribution of information, relieves pressures on urban areas by enabling individuals to work from home or remotesite offices (Garcia, 2009), changes the way we work, and the way we work with one another. In terms of productivity and speed of communications, these changes have been mostly positive (Benham, 1995). But what have been the costs? IT introduces change that creates new ethical issues.

\section{RESEARCH METHODOLOGY}

Data were collected from a convenience sample of 39 students majoring in computer science at the end of the Fall, 2019 semester. The survey form (Appendix) includes eighteen questions and employed a five-point Likert scale ranging from Strongly Disagree to Strongly Agree. The last question in the survey form is used to measure the user's overall satisfaction with required textbook(s). Therefore, bivariate correlations between the underlying dimensions and the user's satisfaction could be calculated and used to assess the marginal importance of each dimension with respect to impact on textbook usage. The questionnaire items were selected based on previous research (Bai, Ola, Eyob, Reese and Akkaladevi, 2019) regarding the factors affecting students' use of textbooks and how they prepare for classes.

In order to answer the opening questions, this study was carried out in three stages. In Stage 1, the principal component analysis using orthogonal rotation was performed on the first twenty items. When those variables are correlated with one another, they are possibly measuring the same construct. In this case, redundancy might exist in those variables. The principal component analysis could reduce those variables into a smaller number of principal components (the underlying dimensions) while those components still accounted for most of the variance in fourteen observed variables. The orthogonal rotation resulted in uncorrelated principal components and made interpretation of those components easier. The number of components was determined by a combination of four approaches - the eigenvalue-one criterion, the scree test (Cattell, 1966), the proportion of variance accounted for (Kim and Mueller, 1978), and the interpretability criterion (Cattell, 1966).

In Stage 2, the survey instrument was tested for reliability and validity. The reliability reflected how well the observed scores collected by the survey instrument were related to the true scores. As the true scores were unknown, the reliability of the survey instrument was defined in practice in terms of the consistency of the observed scores. Cronbach's is one of the most widely used indexes of internal consistency reliability. It is mathematically equivalent to the average of all possible split-half estimates and served as an upper-bound estimate of reliability (Hatcher, 


\section{Issues in Information Systems}

Volume 21, Issue 3, pp. 66-71, 2020

1997). The principal component analysis results could be used to exhibit convergent validity, discriminant validity, and factorial validity (Nunnally, 1978).

In Stage 3, the average scores of items within each dimension (component) was calculated, and the bivariate correlations between the dimensions and the user's satisfaction were used to assess the marginal importance of each dimension affecting the use of textbook and other resources students use to prepare for their classes.

\section{RESULTS}

The number of components initially extracted by the principal component analysis is equal to the number of the variables being analyzed. The initial extraction results are shown in Table 1. The scree plot is shown in Figure 1.

Table 1: Eigenvalues of Principal Analysis

\begin{tabular}{|l|l|l|l|l|l|l|l|l|l|}
\hline Variables & 1 & 2 & 3 & 4 & 5 & 6 & 7 & 8 & 9 \\
\hline Eigenvalue & 5.8 & 3.3 & 1.6 & 1.2 & 1.0 & .8 & .6 & .6 & .5 \\
\hline Variables & 10 & 11 & 12 & 13 & 14 & 15 & 16 & 17 & \\
\hline Eigenvalue & .4 & .3 & .3 & .2 & .1 & .1 & .1 & .1 & .1 \\
\hline
\end{tabular}

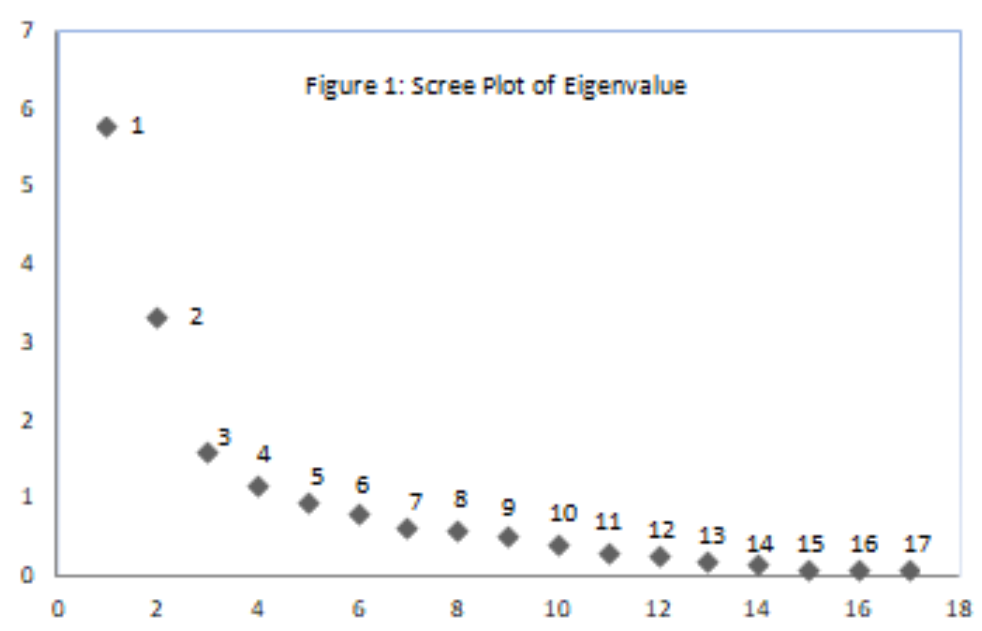

Table 2: Loadings from Orthogonal Rotation

\begin{tabular}{|l|r|r|r|r|r|r|r|r|r|r|r|r|r|r|r|r|r|}
\hline & V1 & V2 & V3 & V4 & V5 & V6 & V7 & V8 & V9 & V10 & V11 & V12 & V13 & V14 & V15 & V16 & V17 \\
\hline $\begin{array}{l}\text { Fac } \\
1\end{array}$ & 18 & $\underline{\mathbf{7 6}}$ & $\underline{\mathbf{6 7}}$ & $\underline{\mathbf{8 1}}$ & $\underline{\mathbf{8 6}}$ & $\underline{\mathbf{8 7}}$ & $\underline{\mathbf{8 4}}$ & 16 & 31 & 20 & -22 & 2 & 25 & -9 & 20 & 35 & 38 \\
\hline $\begin{array}{l}\text { Fac } \\
2\end{array}$ & 3 & 9 & -6 & 4 & 9 & 9 & -3 & $\underline{73}$ & 3 & $\underline{\mathbf{6 8}}$ & $\mathbf{8 2}$ & $\mathbf{8 9}$ & 6 & -26 & $\underline{\mathbf{9 9}}$ & $\underline{\mathbf{7 2}}$ & 9 \\
\hline $\begin{array}{l}\text { Fac } \\
3\end{array}$ & $\underline{\mathbf{8 0}}$ & 35 & 39 & 28 & 14 & 16 & 13 & 22 & $\underline{\mathbf{4 1}}$ & 16 & -23 & -10 & 2 & 26 & 37 & 15 & $\underline{\mathbf{9}}$ \\
\hline $\begin{array}{l}\text { Fac } \\
4\end{array}$ & 23 & 13 & 3 & 13 & 10 & 12 & -8 & -3 & 37 & -6 & 11 & 13 & $\underline{\mathbf{8 5}}$ & $\underline{77}$ & -15 & -16 & 15 \\
\hline
\end{tabular}

A combination of four approaches (the eigenvalue-one criterion, the scree test, the proportion of variance accounted for, and the interpretability criterion) was used in determining the number of components that should be retained. From Table 1, four components have eigenvalues greater than one and were retained by the eigenvalue-one criterion. The scree test looks for a break between the components in terms of eigenvalues. In Figure 1, there was a 


\section{Issues in Information Systems}

Volume 21, Issue 3, pp. 66-71, 2020

break between the first two components and, therefore, one component was retained by the scree test. The approach of "proportion of variance accounted for" retains a component if it accounts for a specified percentage of total variance in the variables being analyzed. This approach has been criticized for its arbitrary critical values (Kim and Mueller, 1987). The critical values usually used in practice are $10 \%$ for individual components and $70 \%-80 \%$ for the combined components (Hatcher, 1997). In Table 1, the eigenvalues represent the amount of variance accounted for by each component. In the principal component analysis, the observed variables were standardized with a mean of zero and a variance of one and, therefore, the total variance in the eighteen variables being analyzed was twenty. From Table 1, the first four components account for approximately $70 \%$ of the total variance while the first three components account for only $63 \%$. It again suggests that four components should be retained.

The orthogonal rotation resulted in uncorrelated principal components and made it easier to interpret those components. Table 2 shows the loadings on components from the orthogonal rotation. The loadings are equivalent to bivariate correlation between the observed variables and the components and communality refers to the amount of variance in an observed variable that is accounted for by the retained components (Hatcher, 1997). For explanation of variables V1 through V17, readers are referred to Appendix: Survey Form.

Examples by (Hatcher, 1997) recommended loading of an item on a given component only if the loading of that item was 0.4 or greater for that component and was less than 0.4 for the other. From Table 2, items 2, 3, 4, 6, and 7 loaded on component 1; items 8, 10,11, 12, 15 and 16 loaded on component 2; items 1, 9, 17 loaded on component 3; items 13 and 14 loaded on component 4. In the survey form (Appendix), questions 2, 3, 4, 6, and 7 all seem to deal with the perceived benefit of a textbook, if the textbook helps prepare for the course work, including tests and homework assignments. Component 1 was subsequently labeled the "Perceived Benefit" component. Questions 8, $10,11,12,15$ and 16 all seem to deal with the other options that help the students prepare for the course; consequently, component 2 was labeled the "Alternatives" component. Questions 1, 9, and 17 deal with easiness to find course related materials from reading assignments, so the component 3 was named "Easiness". Questions 13 and 14 seem to deal with "consistency between lectures and textbook" so it was labeled as "Consistency" component. The interpretability criterion again suggests that four components will be retained. Combining all four approaches, this study has identified four components (underlying dimensions) from the data. The survey instrument was tested for reliability and validity. In this study, according to (Nunnally, 1978), strong correlations between individual items and their components demonstrated convergent validity while relatively weak correlation between individual items and other components demonstrated discriminant validity. Factorial validity assesses whether the survey items (observed variables) form distinct constructs. The principal component analysis showed that the retained items loaded on distinct constructs in terms of interpretation of components, which demonstrated factorial validity. The scale reliability was assessed by calculating Cronbach's a. Cronbach's a reliability estimates were 0.75 , 0.86, 0.63, and 0.64 for the Perceived Benefit, Alternatives, Easiness, and Consistency, respectively. Reliability estimates of the first two components exceeded the value of 0.70 recommended by (Nunnally, 1978), while the reliability estimates of the third and fourth component came close to the value. Finally, the average scores of items within each component were calculated, and the bivariate correlation coefficients between the components and the student's satisfaction with textbook/reading materials were used to assess the marginal importance of each component in improving the use of a textbook. The correlation coefficients and their p-values are shown in Table 3.

Table 3: Correlations between Components and Student’s Satisfaction with Textbook

\begin{tabular}{|l|l|l|l|l|}
\hline & Perceived Benefit & Alternatives & Easiness & Consistency \\
\hline Satisfaction & 0.5329 & -0.7417 & 0.2715 & 0.4667 \\
& $\mathrm{p}<0.0001$ & $\mathrm{p}<0.0001$ & $\mathrm{p}<0.0001$ & $\mathrm{p}<0.0001$ \\
\hline
\end{tabular}

All components were significantly correlated with student's satisfaction of a textbook or reading assignments. The correlation coefficients of the first two components were roughly the same but with different directions; the correlation coefficients of "Easiness" and "Consistency" were substantially lower. Those correlation coefficients indicated that dimensions of "Perceived Benefit" and "Alternatives" were more important in impacting the use of a textbook. It seems that more and more students prefer using "Alternatives" to prepare for their course work. In conclusion, both "Perceived Benefit" and "Alternatives" have strong effects on students' use of a textbook. The predictor "Alternatives" has a larger size of effect than "Perceived Benefit". 


\section{SUMMARY}

This study applied the principal component analysis over survey data. The analysis revealed four underlying dimensions - "Perceived Benefit”, “Alternatives”, "Easiness”, and "Consistency.” The four scales demonstrated high convergent validity, discriminant validity, factorial validity, and internal consistency reliability. Furthermore, correlation analysis indicated that dimensions of "Perceived Benefit" and "Alternatives" were more important in impacting the use of a textbook. The data analysis from the study provides insight into the potential benefits of the use of textbooks. Textbook publishers, educational units, and textbook authors can benefit from the insights revealed by focusing on those dimensions when designing textbooks or teaching materials. The underlying dimensions and their marginal importance could extend knowledge of educational stakeholders in improving the learning and teaching process beyond the scope of questionnaire items.

\section{REFERENCES}

Abratt, R., Nel D., \& Higgs, S. N. (1992). An examination of the ethical beliefs of managers using selected scenarios in a cross-cultural environment. Journal of Business Ethics, 11(1), 29-35.

Benham, H. C., \& Wagner, J. L. (1995). Ethical attitudes of business students and MIS personnel. Proceedings of the ACM SIGCPR Conference [online], Nashville TN USA, 44-49. Available:

www.acm.org/pubs/articles/proceedings/cpr/212490/p44-wagner/p44-wagner.pdf

Gates, B. (1995). The road ahead. New York, NY: Viking Penguin Group.

Aagaard, L., \& Skidmore, R. (2009). College Student Use of Textbooks. Paper presented at the annual meeting of the Mid-South Educational Research Association Baton Rouge, LA, November 6, 2009.

Bai, X., Ola, A., Eyob, E., Reese, S. \& Akkaladevi, A. 2019. Another Look at Textbook Usage by College Students. Issues in Information Systems. Vol 20, Issue 4, pp. 35-44.

Berry, T., L. Cook, N. Hill, \& K. Stevens. 2011. An Exploratory Analysis of Textbook Usage and Study Habits: Misperceptions and Barriers to Success. College Teaching 59 (1): 31-9.

Burchfield, C.M., \& Sappinton, J. (2000). Compliance with required reading assignments. Teaching of Psychology, 27, 58-60.

Cattell, R.B (1966). The scree for criterion and the interpretability criterion, Multivariate Behavioral Research 1 (2), pp. 245-276.

Clump, M.A., Bauer, H., \& Bradley, C. (2004). The extent to which psychology students read textbooks: A multiple class analysis of reading across psychology. Journal of Instructional Psychology, 31, 227-232. Retrieved October 16, 2009, from EBSCOhost Academic Search Premier database.

French, M., Taverna, F., Neumann, M., Kushnir, L. P., Harlow, J., Harrison, D., and Serbanescu, R. (2015). Textbook Use in the Sciences and Its Relation to Course Performance. College Teaching, 63: 171-177, 2015.

Hatcher, H. (1997). A Step-by-Step Approach to Using the SAS System for Factor Analysis and Structural Equation Modeling, SAS Institute Inc., Cary, NC.

Hayes, B. (1991). Measuring Customer Satisfaction Development and Use Questionnaire, ASQC Quality Press, Milwaukee, WI, 1991.

Kim, J., Mueller, C. (1978). Factor Analysis: Statistical Methods and Practical Issues, Beverly Hills, Sage, CA. 
Marchant, G. J. (2002). Student Reading of Assigned Articles: Will This Be on the Test? Teaching of Psychology 29 (1): $49-50$.

Nunnally, J. (1978). Psychometric Theory, McGraw-Hill, New York, NY, 1978.

Podolefsky, Noah \& Finkelstein, Noah. (2006). The Perceived Value of College Physics Textbooks: Students and Instructors May Not See Eye to Eye. The Physics Teacher. 44. 338-342. 10.1119/1.2336132.

Sikorski, J. F., Rich, K., Saville, B. K., Buskist, W., Drogan, O., \& Davis, S. F. (2002) Student use of introductory texts: Comparative survey findings from two universities. Teaching of Psychology, 29, 312-313. Retrieved October 16, 2009, from EBSCOhost Academic Search Premier database.

Starcher, K. \& D. Proffitt. (2011). Encouraging Students to Read: What Professors Are (and Aren’t) Doing about It. International Journal of Teaching and Learning in Higher Education 23 (3): 396-407.

Wandersee, J. H. (1988). Ways students read texts. Journal of Science Teaching, 25, 69-84.

\section{APPENDIX: SURVEY FORM}

Please indicate the extent to which you agree or disagree with the following statements.

I strongly disagree with this statement (SD). ). (need space between word statement and letters SD)

I disagree with this statement (D). (need space between word statement and letter D)

I neither agree nor disagree with this statement $(\mathrm{N})$

I agree with this statement (A).

I strongly agree with this statement (SA)

1. I can easily find materials taught by the professors in class from textbooks or assigned reading materials.

2. I read textbook or reading assignments when I need to understand course materials or prepare for tests.

3. Textbook or reading assignments help me prepare for the test.

4. I read textbooks and reading assignments because they help with understand what the professor taught in class.

5. I read textbooks or reading assignments when I am studying for an exam.

6. I read textbooks or reading assignments when I am working on homework.

7. I read textbooks or reading assignments when I have a specific question.

8. Instead of textbooks or reading materials, I use Google or YouTube when I have a specific question.

9. In most cases, exam questions are from textbooks or reading assignments.

10. I took notes in class.

11. I frequently use Google to search for specific topics for my class.

12. YouTube videos help me understand course materials.

13. Topics and contents covered in class are the same as that presented in the textbooks or reading assignments.

14. If I missed a class, it was easy for me to catch up with the materials because they can be easily found from textbooks or reading assignments.

15. Textbooks or reading materials are lengthy.

16. I have a very busy schedule.

17. When I need to review specific topics, I can easily find them from textbooks or reading assignments.

18. I am very satisfied with the textbooks or reading assignments. 